\title{
EL EQUIPAMIENTO TÉCNICO EN EL TEATRO DEL CENTRO CÍVICO DE LA VAGUADA DE MADRID, ESPAÑA
}

\section{(THE TECHNICAL EQUIPMENT IN LA VAGUADA CIVIC CENTRE THEATRE FROM MADRID, SPAIN)}

Felipe Delgado Laguna, Arquitecto

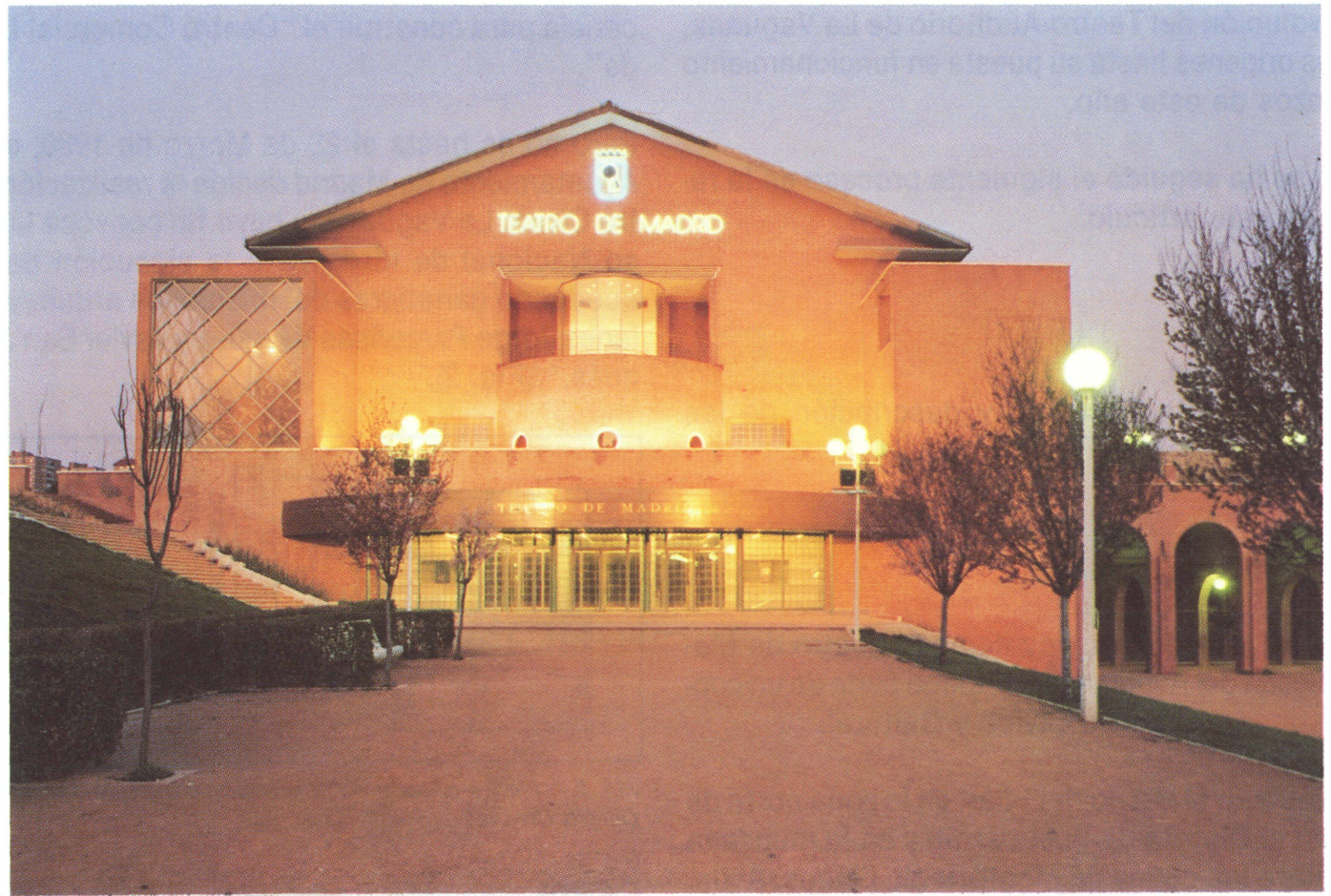

Foto 1.-Fachada principal del Teatro.

\section{RESUMEN}

En este artículo se describen las obras que se han llevado a cabo en el Teatro-Auditorio del Centro Cívico de "La

Vaguada" para dotarle de los elementos equipo-técnicos, así como de instalaciones escenográficas que han permitido,

finalmente, su acondicionamiento y puesta en marcha y que, a la hora de redactar el proyecto, el edificio carecia de ellos.

El trabajo se ha realizado, básicamente, en el escenario y en la sala.

Una vez terminada la obra, ha sido denominado como "Teatro de Madrid".

\section{SUMMARY}

This article describes the works that they have been carried out in the "La Vaguada" Civic Center Theatre-Auditorium for providing it of all technical and mechanical means and the stages installations, which have allowed at last its

conditioning and its start and the time of making the project there wasn't in the building.

The work has been-made, basicment in the stage and the Hall.

When the work was finished, it was called as "Theatre from Madrid". 


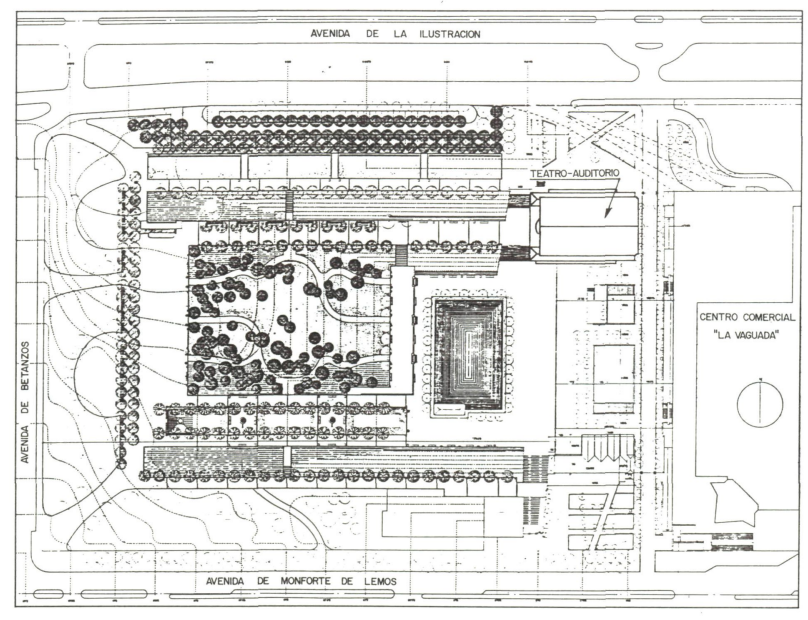

Fig. 1.-Situación del conjunto del Centro Cívico.

\section{PRÓLOGO}

Pretende este artículo dar a conocer al lector la historia y la evolución del Teatro-Auditorio de La Vaguada, desde sus orígenes hasta su puesta en funcionamiento a comienzos de este año.

Para ello se ha seguido el siguiente proceso en la redacción de este artículo.

1. Situación.

2. Antecedentes.

3. Teatro-Auditorio.

4. El Equipamiento Escénico y descripción de las obras.

\section{SITUACIÓN}

El Teatro de la Vaguada, hoy llamado Teatro de Madrid, propiedad del Ayuntamiento, forma parte de un conjunto destinado a Centro Cívico y Cultural.

Se encuentra en el Barrio del Pilar, en la zona norte de Madrid, en el Distrito de Fuencarral, y en la manzana situada entre las calles de Monforte de Lemos, Avda. de Betanzos, Avda. de La llustración y Ginzo de Limia, siendo además colindante con el Centro Comercial de "La Vaguada". (Fig. 1).

\section{ANTECEDENTES}

La calificación de esta manzana como Centro Cívico, viene del Plan General de Ordenación Urbana del Área Metropolitana de Madrid, del 2 de diciembre de 1963, que calificaba a La Vaguada como Centro Cívico y Comercial de distrito.

Pero es en el Plan Parcial del sector de La Vegilla Valdezarza-Vertedero del 5 de octubre de 1973, donde (c) Consejo Superior de Investigaciones Científicas Licencia Creative Commons 3.0 España (by-nc) se definen más los volúmenes, diferenciando tanto er superficie como en usos el Centro Comercial, el Cen. tro Cívico y una extensión destinada a parque.

El 18 de junio de 1975, se presenta un proyecto de or. denación de la manzana, que si bien no obtuvo ningu. na aprobación concreta, representó el punto de partida por el cual el Ayuntamiento consiguió más tarde un área de propiedad municipal para la construcción de un Centro Cívico, satisfaciendo los deseos populares del distrito.

El 30 de junio de 1978, el Ayuntamiento de Madrid acordó aprobar definitivamente, a nivel de estudio de detalle, el Centro Cívico Comercial de esta manzana. Entre las determinaciones del acuerdo se encuentra la obtención, por el procedimiento de cesión gratuita, de una parcela de $16.000 \mathrm{~m}^{2}$ con su correspondiente volumen para la instalación de usos públicos como un Centro Cívico a cargo de la Administración Municipal, siendo el 15 de febrero de 1979 cuando se concede licencia para construir el "Centro Comercial La Vaguada".

Pero no es hasta el 28 de Marzo de 1980, cuando el Ayuntamiento de Madrid decide la realización del Centro Cívico La Vaguada, a cuyo fin convoca un Concurso Nacional de Ideas para la ejecución del mismo, quedando ganadores del mismo los arquitectos catalanes Jorge Parcerisas Vázquez y Javier San José Marqués. ${ }^{\star}$ (Fig. 2).

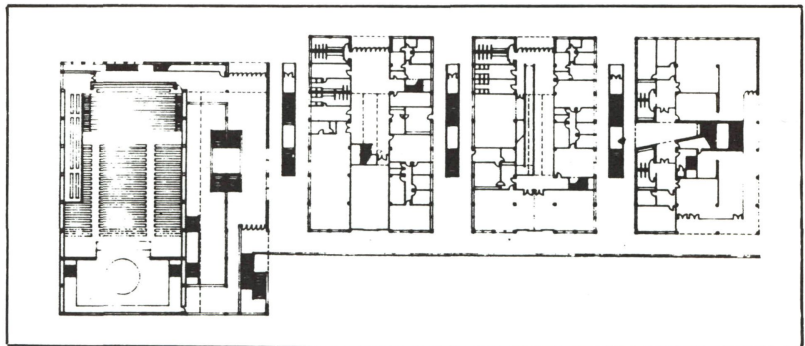

Fig. 2. - Planta general de la solución ganadora del Concurso del Centro Cívico.

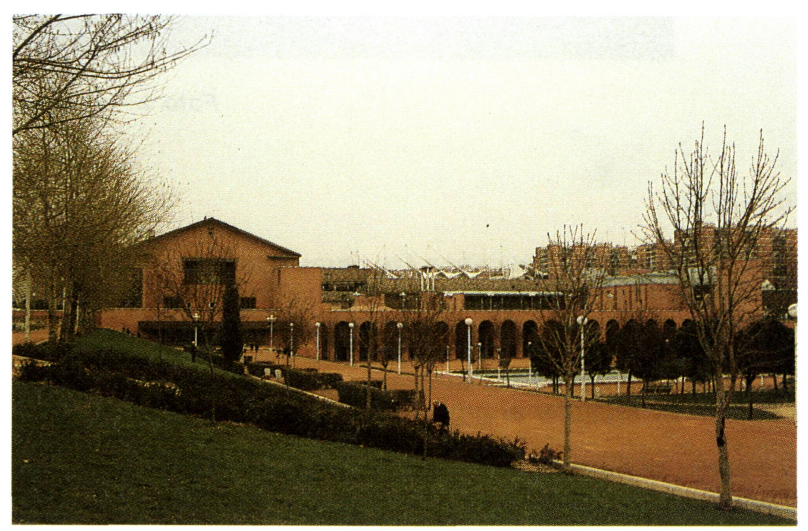

Foto 2.-Vista de conjunto del Centro Cívico.

* Revista "Arquitectura", n. 227 , noviembre-diciembre, 1980. http://informesdelaconstrúccion revistas.csic.es 


\section{EL TEATRO-AUDITORIO}

Dentro de la fragmentación de edificios, de que se compone el Centro Cívico, se estudia aquí con más detenimiento el Auditorio o Teatro.

Es, de todo el conjunto, el edificio que linda con la Avda. de La llustración y que forma el borde oeste.

El Auditorio obedece a la organización clásica y típica de un teatro, es decir: vestíbulos, sala y escenario; con los camerinos y dependencias técnicas de talleres en torno al escenario. (Fig. 3).

De la memoria del proyecto de los autores del edificio vemos que (...) "la zona de vestíbulos formalmente se define al exterior por un amplio mirador hacia el oeste, que flaqueando por dos volúmenes laterales, define la entrega del auditorio con el parque y es por donde se establece el acceso principal, quedando los restantes, a distintos niveles, como salidas de evacuación. En este mismo lado o zona del edificio se localizan el foyer principal y secundario conectados a través de un amplio espacio central que evoca el espacio definido por una cúpula.

En la parte central del volumen se situa la sala. Ésta se entiende como una excavación y está rodeada por dos galerías con sus accesos correspondientes en los costados norte y sur. En el lado oeste se encuentran los foyers y en el lado este está el escenario, permitiendo esta disposición un buen aislamiento de los ruidos exteriores. El trazado de la sala evoca la tradición grecorromana, situando el centro que determina la cavea en el punto medio de la boca del escenario. El tipo al que hace referencia queda alterado por la existencia de palcos laterales. Se introduce la luz natural a través de galerias en las fachadas norte y sur de la parte superior de la sala. Su capacidad es de 900 espectadores.

Como límite entre sala y escenario, se encuentra un espacio intermedio suavemente señalado, que hace las veces de proscenio.

Entre el falso techo de escayola que forma con sus casetones acústicos el techo de la sala nos encontramos con (...) "dos amplias galerías de iluminación artificial del escenario" (iluminación escénica de espectáculos).

Un amplio foso para la orquesta señala el final de la cavea. Este foso puede cubrirse mediante la elevación de su suelo, y tomando parte de la superficie del escenario puede obtenerse un podium para orquesta y coros para conciertos (...)".

El escenario, añade el autor de este artículo, es un cuerpo claramente funcional y amoldado en su forma al vo- lumen general del edificio cuyos autores al expresar el contenido del edificio al exterior hicieron que no se reflejara la caja del escenario en cuanto a su volumen. Esto lleva sin embargo a crear un problema de altitud de la misma frente a las proporciones ideales en la relación altura-escenario; altura-embocadura; tamaño de la sala. No obstante pensamos que queda el escenario lo suficientemente capaz para las representaciones que se pretenden llevar a cabo.

Lateralmente al escenario se encuentran los camerinos, comunicados entre sí por unas escaleras que llevan también al foso.

Tras el escenario, y volviendo a la memoria de los autores del edificio (...) "se situa un amplio almacén-taller, con acceso directo a la galería-parking del conjunto permitiendo mediante un muelle de carga y descarga el acceso de los grandes decorados" (...) a través de una puerta con acceso directo a la chácena del escenario. En esta galería se pueden descargar camiones con decorados de gran tonelaje y capacidad.

Anexo al auditorio nos encontramos con un núcleo destinado a oficinas, que se concibieron en un principio para centro administrativo del conjunto. Hoy día se usan para despachos de dirección técnica y artística del teatro y que, al estar conexionado con éste, sirve de entrada general para técnicos, artistas y personal administrativo del auditorio a través de una única entrada desde el parque.

\section{EL EQUIPAMIENTO TÉCNICO}

En los años 1987 y 1988, se construye el auditorio dentro de las fases en que se concibió la construcción del conjunto del Centro Cívico.

Sin que sea preciso mencionar las causas, el auditorio quedó inconcluso en muchos aspectos, entre ellos el de equipamiento técnico.

Así estuvo durante bastante tiempo, hasta que, en agosto de 1989, el Ayuntamiento de Madrid, convoca un nuevo concurso para la redacción de un proyecto que complete el auditorio en su faceta técnica y pueda ser utilizado, redactando para ello el "Pliego de Condiciones Técnicas que habrá de regir en el Concurso Público para la Redacción del Proyecto y la Ejecución de las Obras de Equipamiento Técnico en el Teatro de La Vaguada".

Este concurso era en realidad un concurso destinado a empresas, teniendo que presentar un proyecto de ejecución firmado por un arquitecto. 
Estado definitivo de las plantas del edificio, una vez incluido el equipamiento técnico $y$ realizado obras de mejora (Figs. 3a, b, c y d).

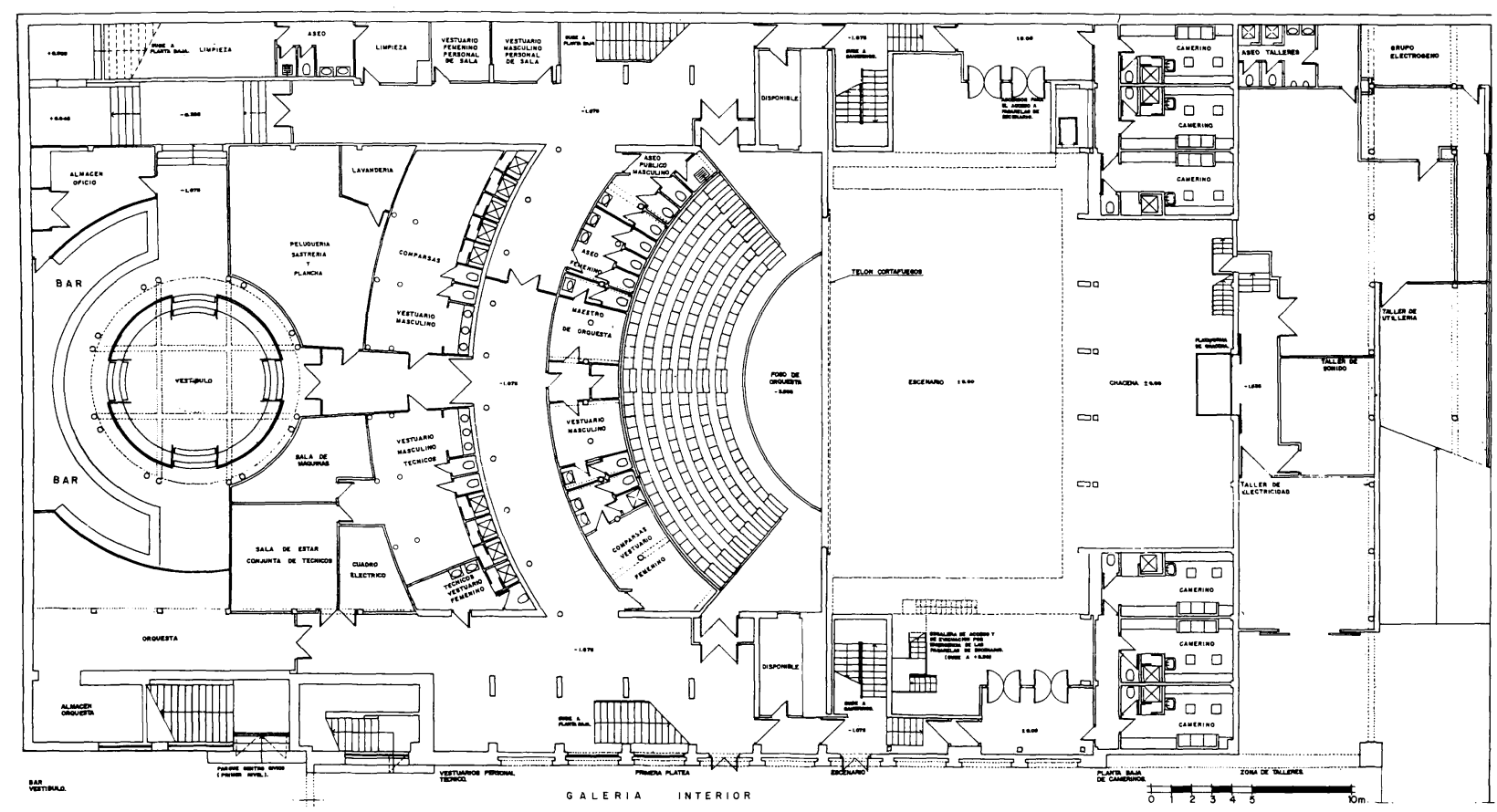

Fig. 3.a

Planta de semisótano

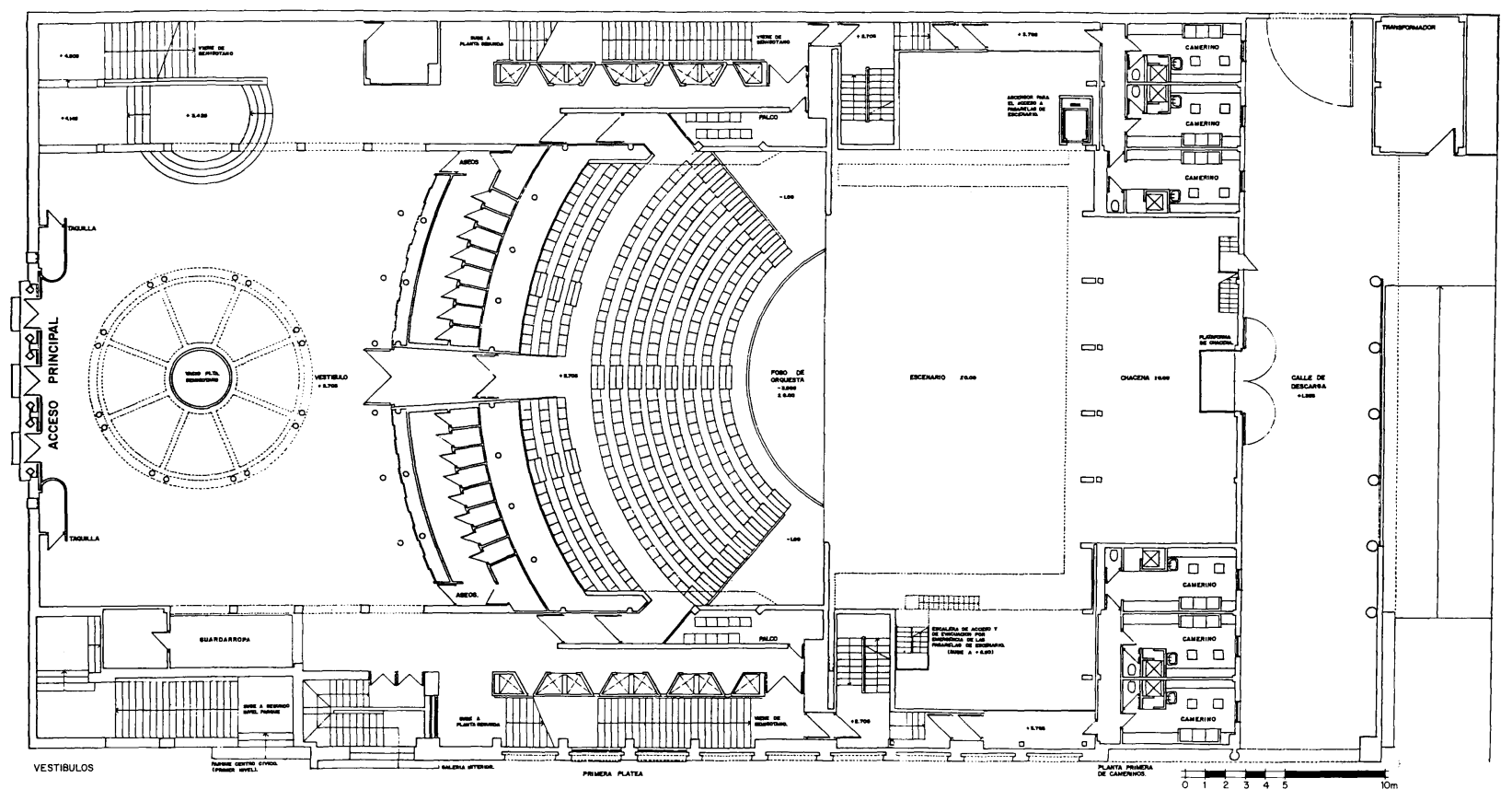

Fig. 3.b 


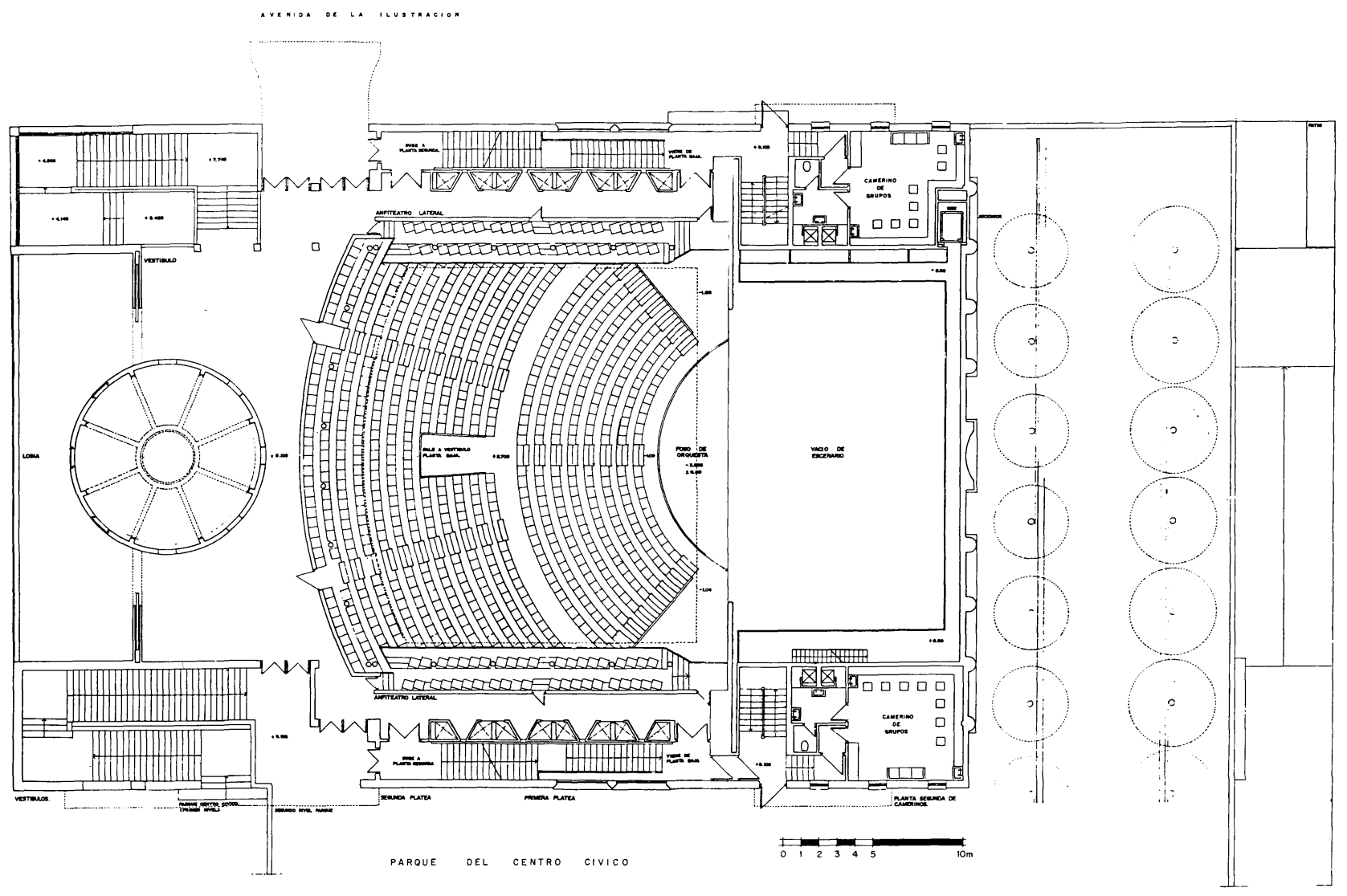

Fig. 3.c

Planta primera

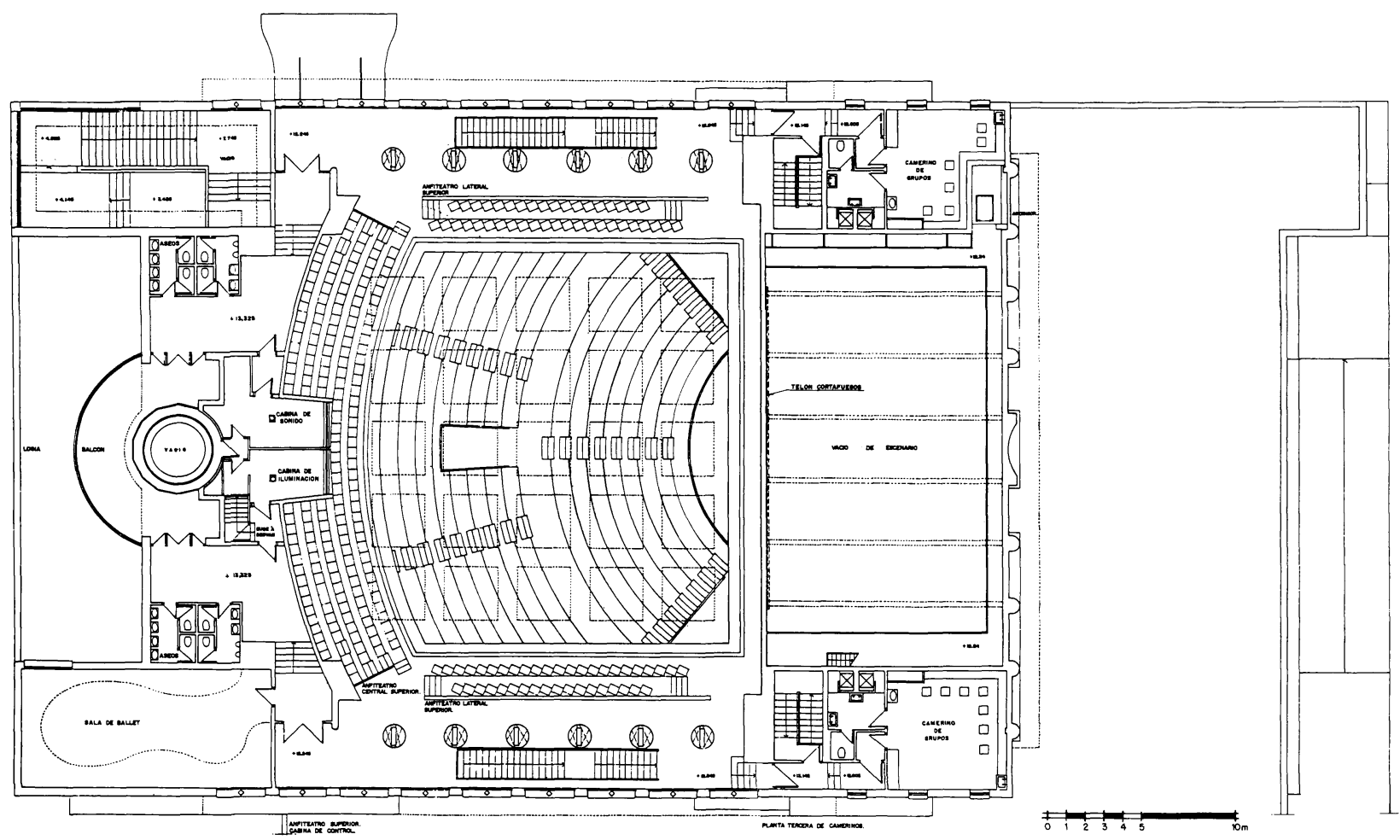

Fig. 3.d

(C) Consejo Superior de Investigaciones Científicas Licencia Creative Commons 3.0 España (by-nc) 

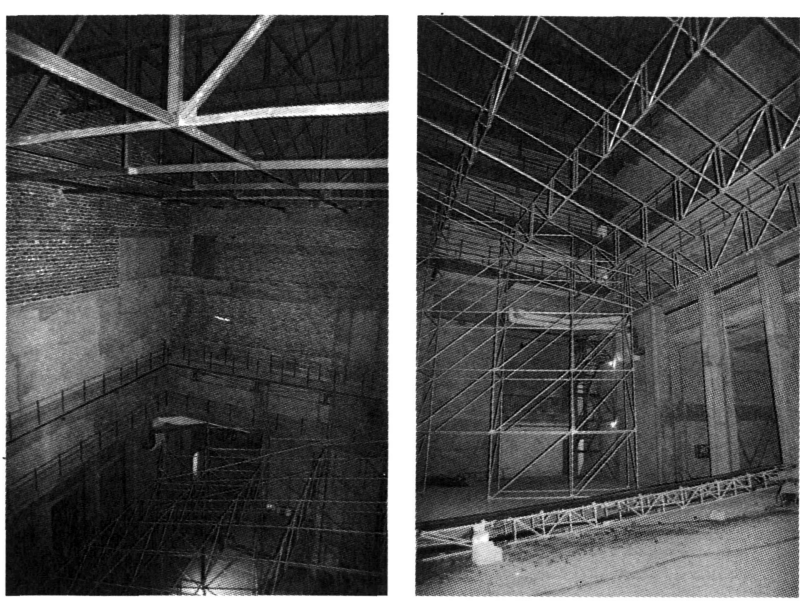

Foto 3.-Estado de la estructura de tramóya y de pasarelas en el interior del escenario.

El Teatro de La Vaguada se encontraba en aquellas fechas con sus elementos constructivos básicos terminados, pero pendiente de la ejecución de las obras de equipamiento técnico tales como iluminación, sonido, tramoya, instalaciones especiales y de seguridad, telar y telonaje, que definieran su utilización como sala de usos diversos, es decir, que en el mismo pudiera representarse tanto Opera, como Zarzuela, Ballet, Comedias Musicales, Conciertos y Teatro.

Cuando el equipo redactor entró en el Teatro por primera vez atendió de entrada a las bases del concurso, pero se pudo comprobar que había quedado inacabada e incompleta la estructura de tramoya del escenario en cuanto a pasarelas, incluso con errores en su concepción como mala accesibilidad y mala ubicación de las mismas. (Foto 3).

Las cerchas de la cubierta del escenario, tampoco tenían el diseño más apropiado para albergar la maquinaria escénica habitual para la elevación de decorados, cumpliendo tan sólo la función de sustentación de la cubierta.

En un escenario, toda estructura, todo espacio y toda proporción ha de ir pensada en función de la escenografía. Existe en su concepción una fuerte separación entre el espacio escenográfico y el espacio del espectador que se situa en la sala. Las únicas servidumbres entre uno y otro son las obligaciones visuales y las acústicas que delimitan muchas veces la forma de la sala, y con ello el espacio intermedio que es el proscenio, aquí prácticamente inexistente, y sobre todo la dimensión de la embocadura.

Olvidarse de estas servidumbres supone en arquitectura teatral encontrarse con errores de concepción, pues en ella el edificio debe nacer de dentro hacia afuera.

Otro error de concepto comprobado fue que entre la chácena o parte posterior del escenario y éste existían, y de hecho existen todavía, cuatro pilares con junta de dilatación que soportan la fachada exterior del escenario en su parte trasera. Esto resta muchas posibilidades escénicas al escenario ya que si de proporción en altura no es adecuado, la relación con su embocadura no es tampoco la más apta, y de profundidad es corto; pues dadas las actuaciones teatrales que se pretendían en las bases, y que de hecho hoy ya se están realizando, vendría bien tener más amplitud de fondo con lo que la escenografía ganaría en perspectiva; pero esta situación de los pilares es insalvable.

Nos encontramos también con que las escaleras de acceso a los camerinos están demasiado incorporadas hacia el escenario y concretamente a su embocadura, esto hace que los laterales de ésta llamados hombros del escenario sean muy pequeños, limitando la circulación de perscrájes por este espacio; motivo por el cual la mesa del regidor, que en esta obra se ha instalado, no se puede poner junto a la embocadura sino más retrasada, lo que condiciona el control del regidor.

De alguna manera estos inconvenientes han condicionado el resultado final.

El plazo de presentación para la redacción del proyecto fue de dos meses a partir de la fecha en que salieron publicadas las Bases en el B.O.C.M. el 25 de agosto de 1989.

El autor de este artículo se presentó a este concurso, acompañando a la empresas Cubiertas y M.Z.O.V. y Crespo y Blasco, empresa esta última de electricidad, siendo éste el único equipo que se presentó.

El concurso fue declarado desierto en diciembre de 1989 y, finalmente, adjudicado al firmante de este artículo en junio de 1990, produciéndose la consiguiente nueva redacción de proyecto, dado que, siguiendo las indicaciones del Departamento de Proyectos de Edificación del Ayuntamiento de Madrid, hubo que modificar algunos aspectos de las bases iniciales que incidían sobre el presupuesto.

La dirección de las obras se ha llevado compartida entre el arquitecto, autor del proyecto y de este artículo, y el arquitecto jefe del Departamento de Proyectos de Edificación del Ayuntamiento de Madrid, D. Guillermo Costa Pérez-Herrero. Las obras se empezaron en marzo de 1991, finalizándose en enero de 1992, con la inauguración oficial con un concierto el 12 del mismo mes.

\section{Descripción de las obras}

Para la realización de los objetivos requeridos, se realizaron las siguientes obras: http://informesdelaconstruccion.revistas.csic.es 


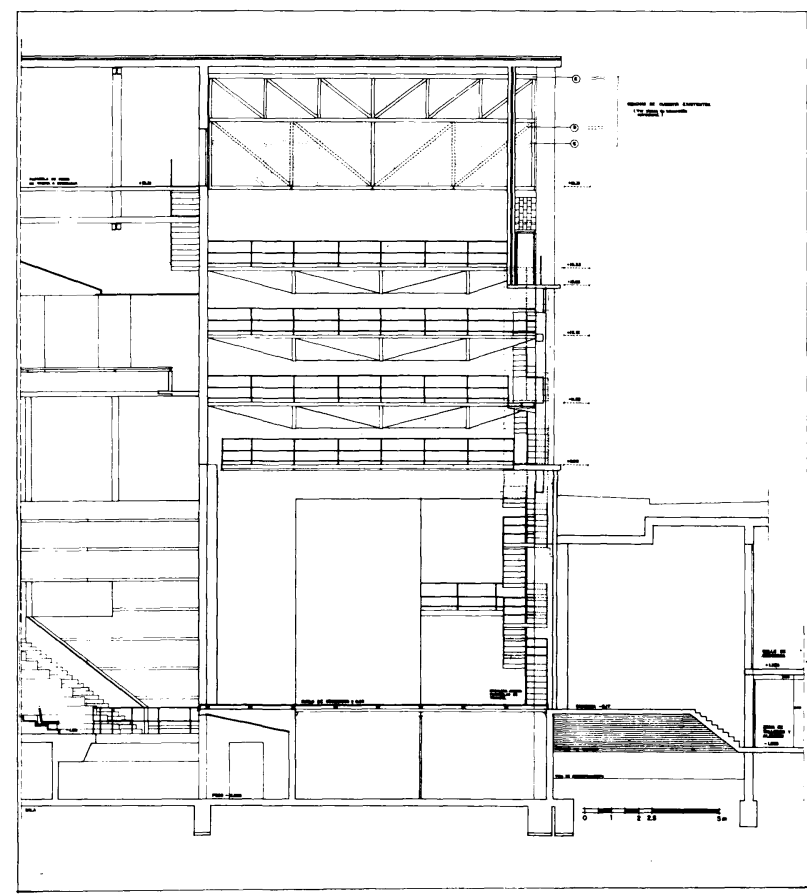

Fig. 4.-Sección longitudinal del estado primitivo del escenario.

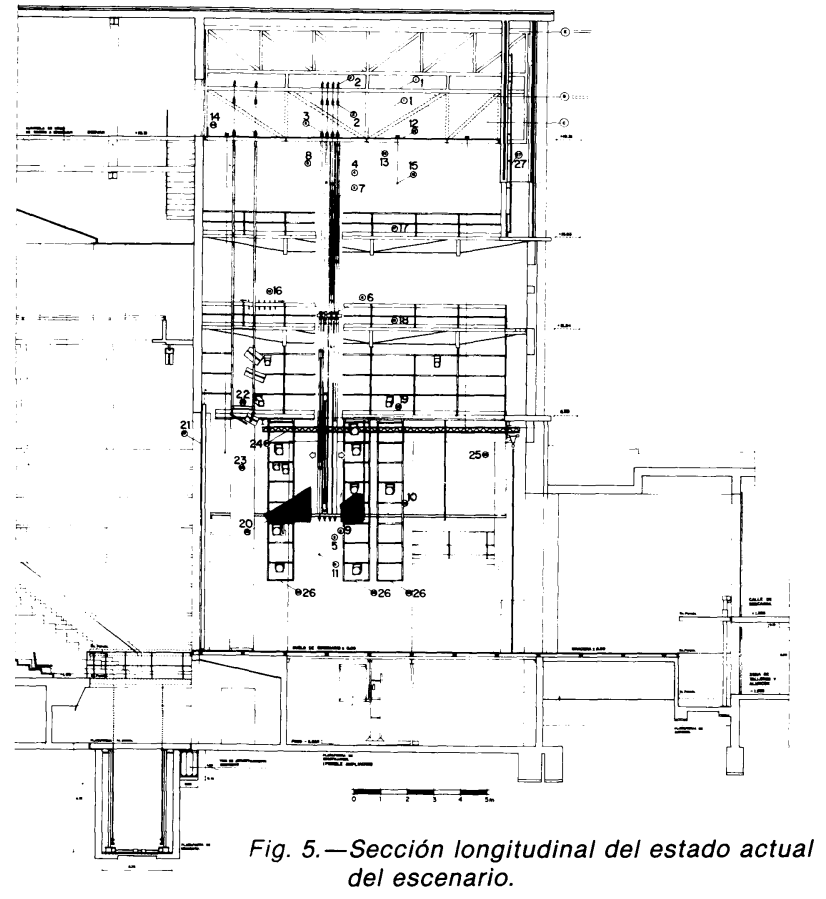

1.-Estructura poleas de tiro. 2.-Poleas de tiro. 3.-Poleas de cabeza. 4.-Carro contrapesado. 5.-Cable. 6.-Freno de seguridad. 7.-Contrapesos. 8.-Guía de deslizamiento. 9.-Polea de reenvío. 10.-Bandeja de reenvio. 11.-Barra contrapesada. 12.-Peine. 13.-Estructura soporte de peine. 14.-Tiro manual. 15.-Barra de tiro manual. 16.-Aspa de atado. 17.-Galeria de carga. 18.-Galería de trabajo. 19.-Galería de iluminación. 20.-Mallazo metálico de protección. 21.-Telón cortafuegos. 22.-Puente de luces. 23.-Torre de iluminación. 24.-Viga rodante lamas laterales. 25.-Viga rodante lamas de fondo. 26.-Es. calera de luces móvil. 27.-Escalera de pates.

Fig. 6. - Sección longitudinal del conjunto del edificio en su estado actual.

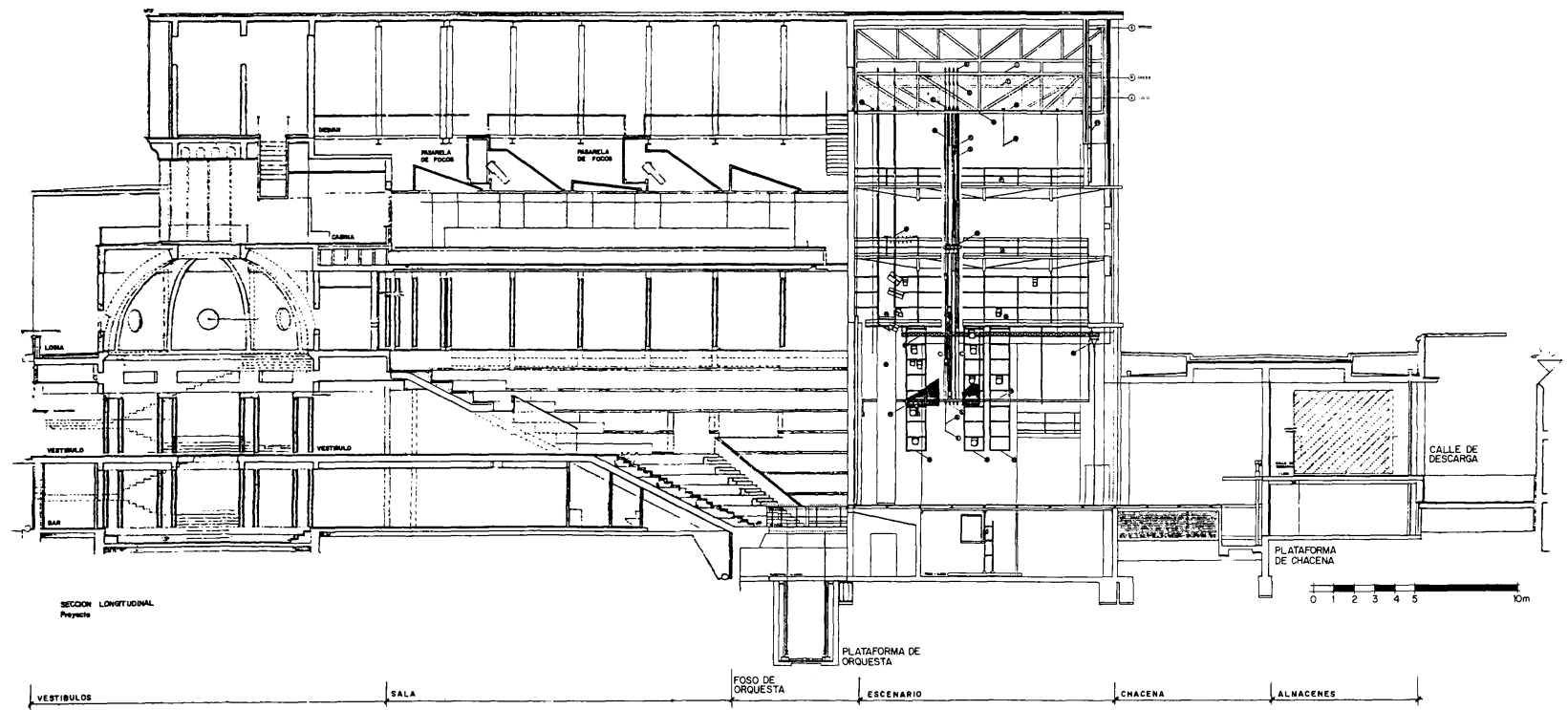

1.- Reforma estructural del escenario.

2.- Solución de elevación de decorados.

3.- Elementos hidráulicos.

4.- Cortinajes y suelos escénicos.

5. - Instalación de Electrificación.

6. - Instalaciones Especiales.

7.- Instalaciones de Seguridad.

8.- Equipamiento.

9.- Otras mejoras incluidas.

10. - El tratamiento acústico.

\section{Reforma estructural del escenario}

\section{a) La reforma de las pasarelas}

Se llama hombro derecho a la parte derecha del escenario mirando desde la posición del espectador. Existían antes del comienzo de las obras unas pasarelas metálicas en forma de cercha situadas a las cotas $+8,90 ;+11,32 ;+13,31$ y la última con dos niveles a $+15,63$ y $+16,33$, siendo la cota $\pm 0,00$ la de suelo de escenario. 
Para acceder a las mismas, en algunos casos y tras utilizar una escalera, había que saltar por encima de unas vigas de arriostramiento de 30×100 del edificio en esta zona del escenario, habiéndo quedado como deficiencia constructiva.

Esto originó replantear las cotas de las pasarelas del escenario teniendo que modificar altitudes, desempotrando de los muros las pasarelas que había y, mediante trácteres sujetos a la estructura de cubierta, de la que posteriormente trataremos, colgarlas y subir o bajar las pasarelas y situarlas en las cotas correctas eliminando así el problema antes descrito.

Quedaron las pasarelas a las nuevas cotas de $+8,90$; $+12,24 ; y+15,63$, y enrasándolas con la cara superior de las vigas. (Figs. 4, 5 y 6 ).

En el hombro opuesto, el izquierdo, tan sólo existían las pasarelas $+8,90 y+11,32$. La primera se mantuvo, pero la $+11,32$ pasó a ser la $+12,24$. La pasarela que ocupaba la cota $+13,81$ del hombro derecho pasó a ser la $+15,63$ del hombro izquierdo.

Se rehizo la $+12,24$ en su frente y se prolongó la cota $+15,63$, incorporando el tramo de pasarela que daba a la fachada trasera del escenario o fachada este al interior del mismo, pues no era lógico "salir a la calle" a través de una pasarela de un escenario para luego tener que volver a entrar, lo que llevó a modificar en parte la fachada posterior del escenario. (Fotos 4a y b).

Con ello, quedaron completos todos los tramos de pasarela del escenario y situadas todas las pasarelas en su nivel, quedando unidos así los dos hombros, condición básica para un buen acceso del personal técnico a esta altura del escenario para el desarrollo de sus trabajos.

Se demolió la escalera de acceso a estas pasarelas y se sustituyó por un ascensor-montacargas con la primera parada en el escenario, ya que en este hombro se desarrolla todo el trabajo de contrapesado de decorados sirviendo el ascensor para subir cómodamente el material. En el otro hombro se producen los accesos a través de un nuevo trazado de escaleras metálicas desde el escenario, que hacen que todas las galerías queden comunicadas entre sí.

\section{b) La reforma de la estructura de cubierta}

En la cubierta del escenario, tenemos un conjunto de cerchas las $C, D, y$ según la Fig. 7.

De estas cerchas se colgó el nuevo telar que, en el momento de iniciar las obras, carecía de él y a una cota de $+19,31$ con relación al escenario.

(C) Consejo Superior de Investigaciones Científicas

Licencia Creative Commons 3.0 España (by-nc)

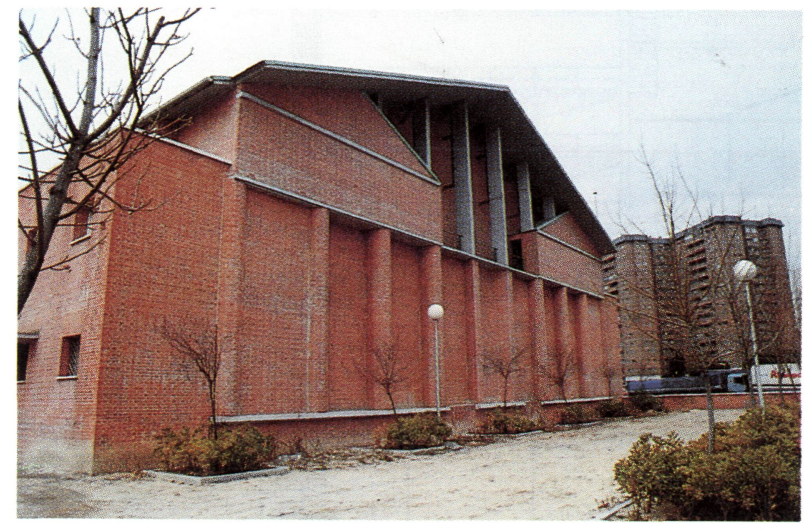

a

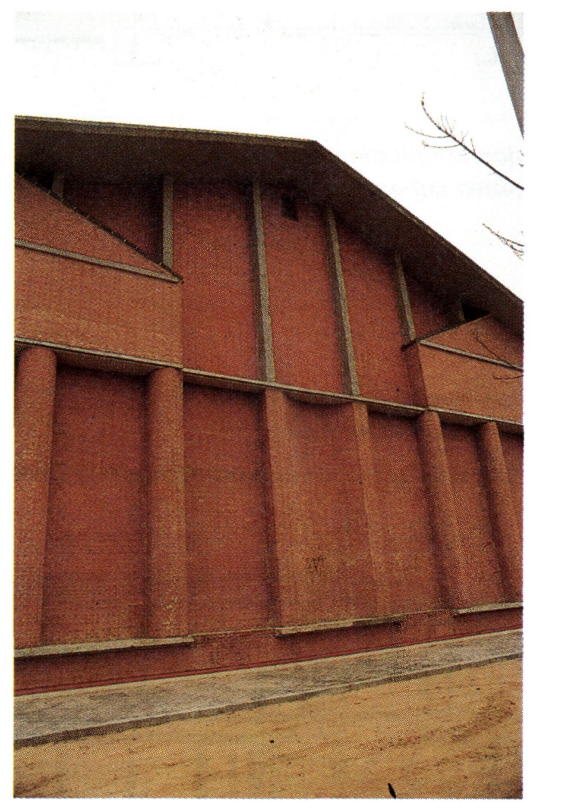

Fotos 4.-Fachada posterior: a) Estado primitivo y b) estado actual.

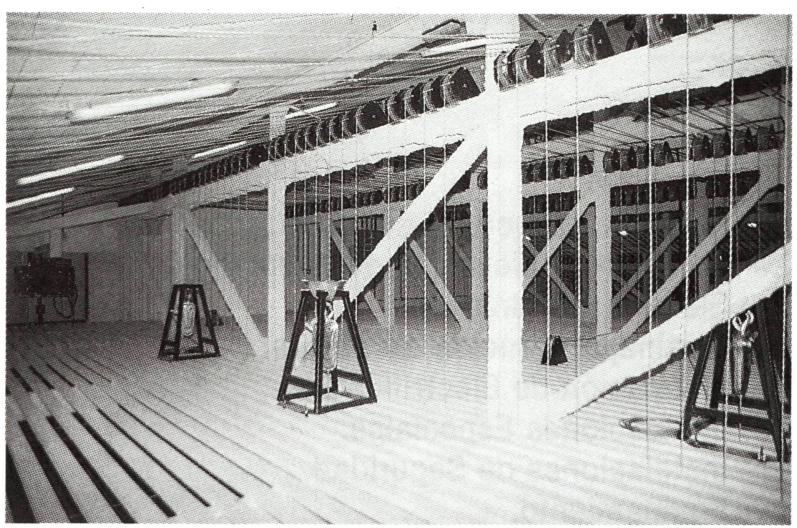

Foto 5.-Estado definitivo de las cerchas de estructura de cubierta y peine. Colocación de poleas y sujeción de decorado. http://informesdelaconstruccion.revistas.csic.es 


\section{ESTADO PRIMITIVO}
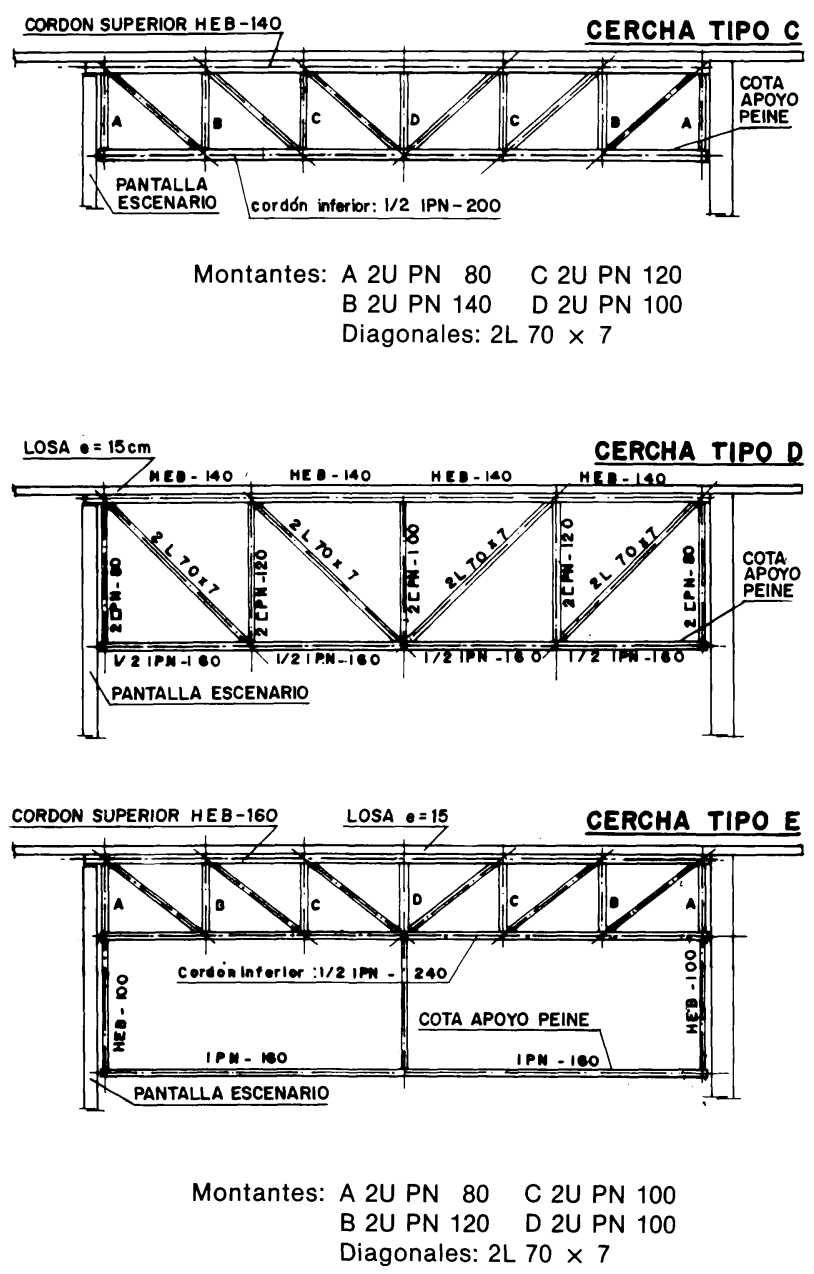
Diagonales: $2 \mathrm{~L} 70 \times 7$

\section{ESTADO ACTUAL}
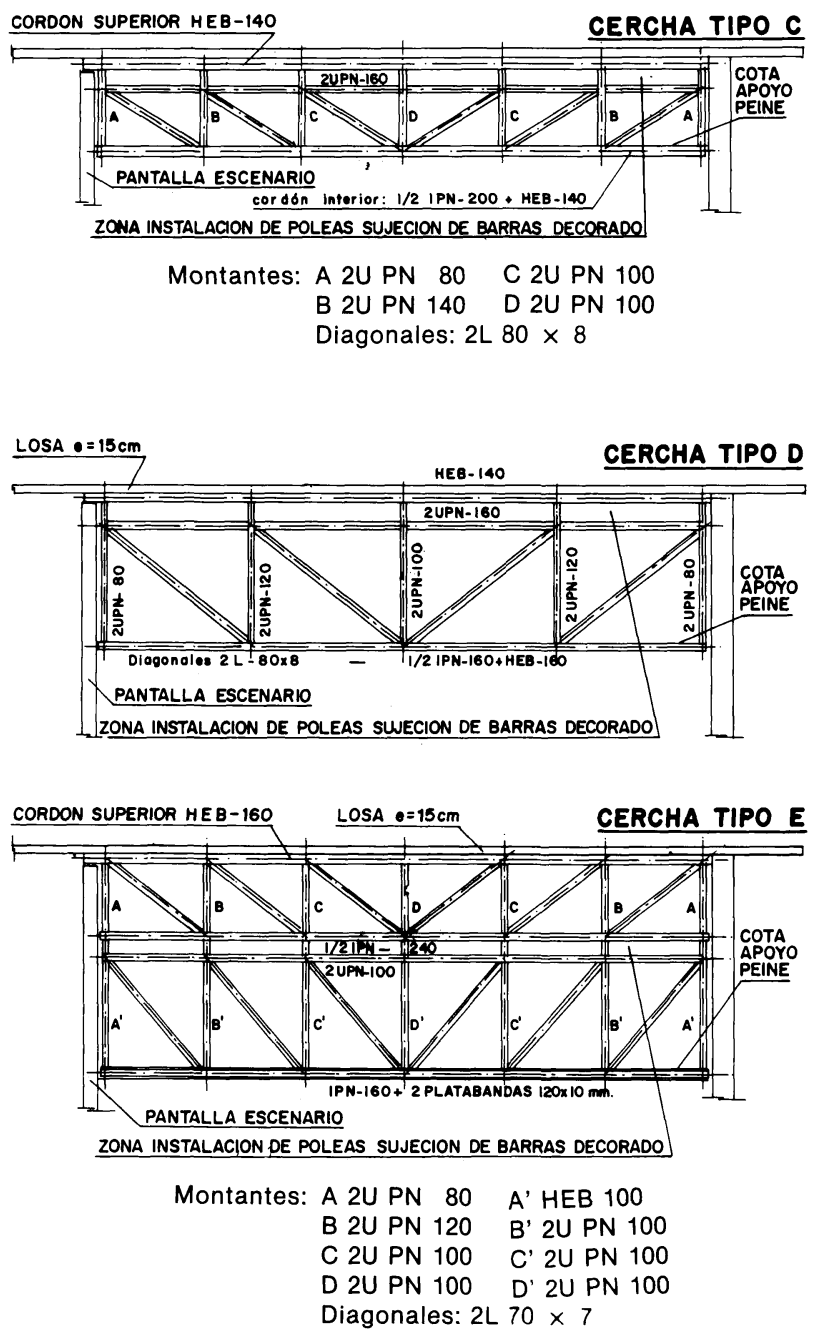

Fig. 7.-Estructura de cerchas de escenario.

El telar o peine, es el elemento de la tramoya que, teniendo una configuración a modo de parrilla, sustenta todos los elementos escénicos como decorados, luces, bambalinas, etc. Éste es metálico formado por perfilería UPN 80 , apoyándose en los cordones inferiores de las cerchas.

La parte superior de las mismas (cordones longitudinales) se modificaron de modo básico, creando un segundo cordón longitudinal superior implicando la modificación de los cordones inclinados según el cálculo de cargas previsto.

Esta reforma estuvo condicionada porque al tener que instalar las poleas de sujeción de las barras de decorado sobre las cerchas, como es habitual y necesario en estos casos, y no encontrarse alineados los nudos de la estructura en relación con la línea paralela a la embocadura, hubo por ello que rehacer el diseño de la estructura. Por lo tanto, en un principio, no estaban diseñadas para albergar la maquinaria escénica con un máximo de posibilidades. (Fig. 7).
Al realizar un segundo cordón longitudinal permite dejar paso libre a los cables de las poleas para conseguir un mayor número de barras de decorado. (Foto 5).

No obstante existen algunos cruces insalvables, obligando a instalar poleas por debajo del peine.

Para la realización de esta obra, que fue bastante compleja, y que en realidad ha sido básica para una correcta concepción del escenario, fue preciso montar un andamio desde la cota $+0,00$ hasta llegar a la cota deseada de $+19,31$. Una vez montado, se fueron modificando, suplementando y corrigiendo los cordones estructurales como hemos comentado. Se contó con la colaboración de una empresa especializada en control de estructuras, y que en todo momento observó el comportamiento de la estructura durante su realización.

\section{Solución de elevación de decorados}

La elevación de decorados se resuelve contrapesando las barras de decorado. 


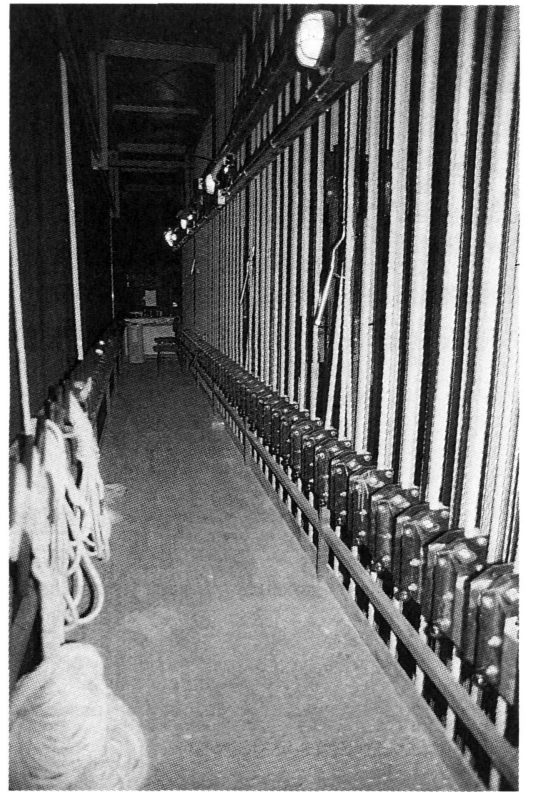

Foto 6.-Pasarela de realización del trabajo de contrapesado.

Por las características y dimensiones del escenario se han obtenido 57 barras de decorado, utilizándose algunas de ellas para barra de luces, estando diseñadas todas ellas para soportar un peso de $500 \mathrm{~kg}$.

La maquinaria del contrapesado, de accionamiento manual, tiene como objeto el intentar equilibrar el peso del decorado, para que el esfuerzo del tramoyista en la elevación de los mismos durante las funciones sea mínimo, o casi mínimo, permitiendo ahorrar tiempo, trabajo y esfuerzo humano.

Este equilibrio, lo realiza el tramoyista introduciendo contrapesos de $12,5 \mathrm{~kg}$ en los carros bastidores, de cada barra de decorado, y a lo largo de las pasarelas de trabajo, hasta conseguir el equilibrio como una balanza. De ahí la importancia que tiene el ascensormontacargas para distribuir todo el material necesario por las distintas pasarelas, y facilitar el movimiento del personal por las distintas pasarelas donde se realiza el trabajo. (Foto 6).

\section{Elementos hidráulicos}

\section{a) Plataforma de chácena}

En la zona de carga y descarga del escenario, en la chácena, se ha construido una plataforma de carga y descarga de decorados.

Esta plataforma tiene tres niveles de parada: Uno a nivel de la calle-muelle de carga y descarga desde donde se da acceso a los grandes decorados a través de una puerta con acceso directo a la chácena del escenario. En esta galería pueden descargar camiones de gran tonelaje y capacidad. Otro nivel de parada es a cota de escenario para descargar en él y, por último, un tercer nivel a cota de almacenes.

Se ha tenido que abrir una nueva puerta para que el personal técnico pueda acceder desde el escenario a la calle-muelle de descarga.

\section{b) Ascensor-montacargas hidráulico}

Apto para una carga de $1.000 \mathrm{~kg}$ sirve esencialmente para subir material como contrapesos, focos, etc. a las pasarelas de trabajo disponiendo de varias paradas: $+0,00$ a nivel de escenario y en las pasarelas $+8,90$; $+12,24 ;+15,63$, pero debido a la forma de la cubierta de dos aguas no se puede llevar el ascensor hasta el peine.

El acceso de material al peine se realiza en cambio gracias a un polipasto o motor colgado de la estructura que permite subir material hasta el peine.

Si no se hubiera, en origen, dejado la cubierta del escenario al mismo nivel que la de la sala, se hubiera podido resolver este problema de mejor modo, permitiendo que el ascensor subiera hasta el nivel de la cota de peine, e incluso haber elevado la cota del mismo en relación con la del escenario ya que en la actualidad es algo corta, debiendo ser casi el triple de la de embocadura, cuando en realidad es de 2,15 con lo que hay que falsear la embocadura con unos telones o bambalinas al efecto, consiguiéndose la proporción adecuada.

\section{c) Plataforma de orquesta}

Ésta, que también es móvil, tiene tres paradas: una a nivel de foso de orquesta, otra a nivel de sala o patio de butacas y una última a nivel de escenario.

La primera parada sirve de base para crear el suelo del foso destinado a ubicar a la orquesta en zarzuelas y óperas.

Con la segunda se consigue dejar la plataforma a nivel de patio de butacas para dar, si se quiere, una conferencia e incluso un recital de piano en la misma sala.

$Y$, finalmente, con la última posición podemos prolongar el escenario para dar desde allí un concierto de orquesta, ubicada dentro del escenario.

Para la realización de la misma, hubo que hacer un cajeado del suelo hasta llegar a una cota de $-4,80 \mathrm{~m}$, desde el nivel de cota de foso de orquesta situado este a $-3,595 \mathrm{~m}$ con respecto al escenario. Se llegó a rozar el nivel freático, por lo que fue preciso instalar un sistema de bombeo y achique de aguas con desagüe al alcantarillado. (Foto 7 ).

http://informesdelaconstruccion.revistas.csic.es 


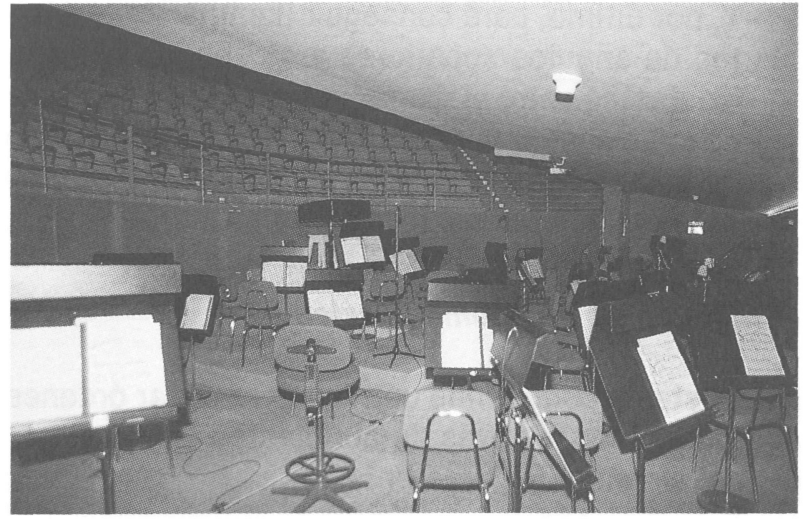

Foto 7.-Foso de orquesta.

\section{Cortinajes y suelos escénicos}

Se han instalado cortinajes propios de las representaciones que se han de llevar a cabo, así como un suelo de goma para representaciones de ballet.

\section{Instalación de electrificación}

El capítulo de electricidad ha comprendido básicamente los siguientes trabajos:

- Ejecución de acometidas.

- Sistema de iluminación básica.

- Sistema de iluminación escénica.

\section{a) Ejecución de acometidas}

La potencia máxima demandada para atender las necesidades ha sido de $1.430 \mathrm{KVA}$, para un suministro normal, y de 70 KVA para suministro complementario.

Para satisfacer las necesidades de la instalación ha sido necesario modificar los componentes del transformador general del conjunto del Centro Cívico en las celdillas que repercuten a la acometida del teatro. Se ha dejado, por lo tanto, la antigua acometida para dar servicios de alumbrado ordinario a las partes del edificio que ya lo tenían.

Se ha instalado también un grupo electrógeno que sirve de doble acometida a los servicios básicos en un momento de falta de fluido.

\section{b) Sistema de iluminación básica}

El sistema de iluminación comprendió el alumbrado normal u ordinario y el de señalización y emergencia.

El alumbrado normal u ordinario instalado ha sido el que proporciona el nivel de iluminación necesario, pen- sado en función de poder realizar las tares propias de un escenario como montajes, desmontajes, y el trabajo de control de movimiento de decorados en las pasarelas en un momento de las representaciones.

El alumbrado de señalización y emergencia ha sido el propio y necesario para señalizar correctamente las vías de evacuación del personal hacia el exterior.

\section{c) Sistema de alumbrado escénico}

El sistema de alumbrado escénico consiste en iluminar el cuadro de escena.

\section{Se ha conseguido electrificando:}

1.-Las galerías interiores de dentro del escenario, normalmente las primeras en altitud, en nuestro caso la $+8,90$ con tomas de $2,5 \mathrm{kw}$ de potencia, donde se conectan los focos más convenientes según la escenografía a representar. Se han instalado en esta zona unas escalerillas y barandillas especiales para situar focos en la primera pasarela, tres en cada lateral. (Foto 8).

2.-Cinco barras de decorado se complementan con otras propias para situar focos que permiten la iluminación interior de modo cenital. (Foto 9).

3.-Se han instalado barras de sustentación de focos en el interior de la sala entre los palcos laterales y la platea, consiguiendo una iluminación entre rasante y en picado. (Fotos 10a y b).

4.-Para conseguir efectos lumínicos más en picado se han construido barras de focos en el peto del último anfiteatro.

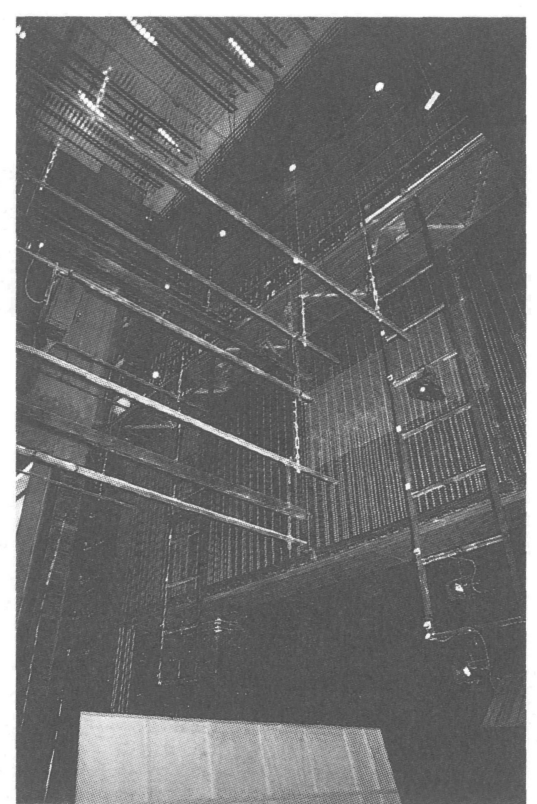

Foto 8.-Escalerillas laterales de sujeción de focos.

http://informesdelaconstruccion.revistas.csic.es 


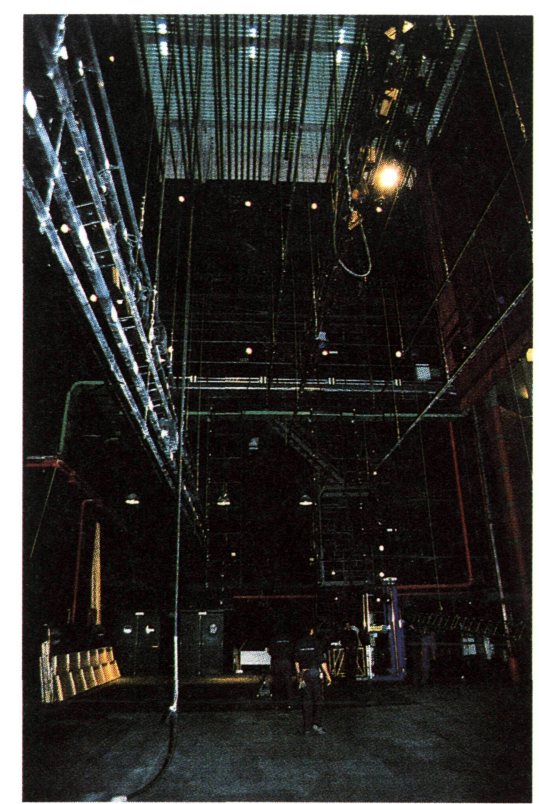

Foto 9.-Barras de decorado con complemen. to para focos.

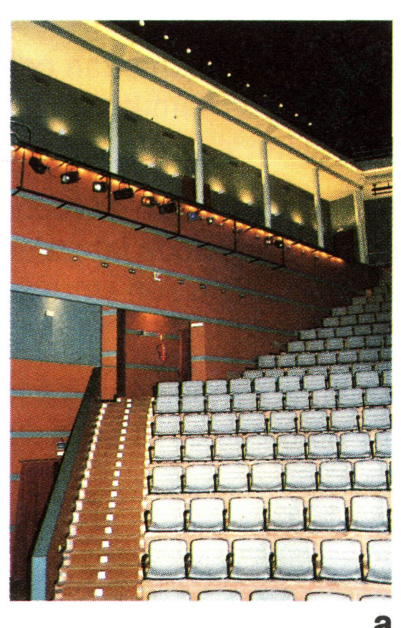

a

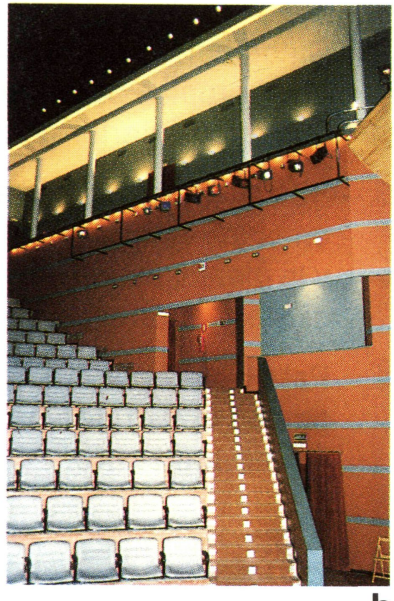

Fotos 10a y b.-Barras de luces en el interior de la sala.
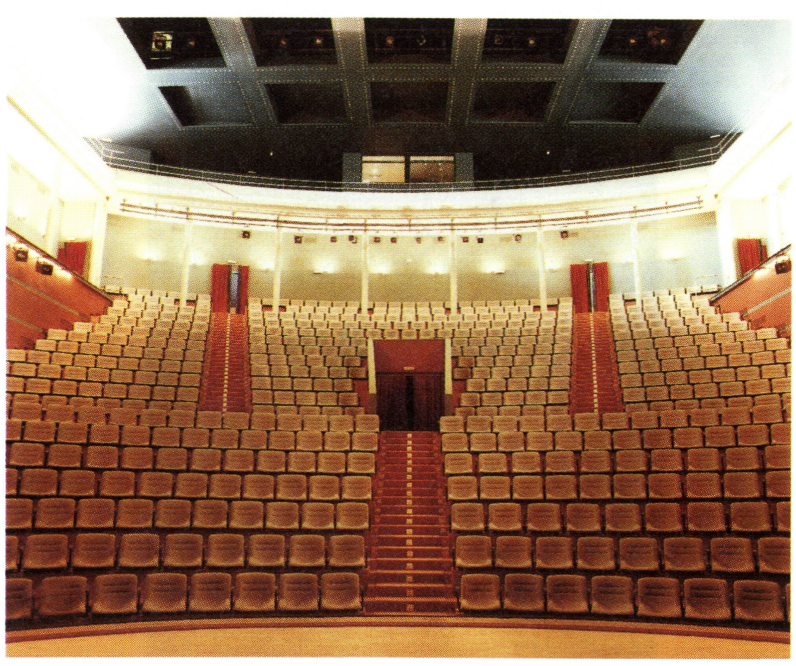

Foto 11.-Galería de focos en techo de sala y en voladizo último anfiteatro.

(C) Consejo Superior de Investigaciones Científicas Licencia Creative Commons 3.0 España (by-nc)
5.-Y, por último, para conseguir iluminación o efectos de ángulos superiores a $45^{\circ}$ en las galerías existentes entre el desván y el techo de escayola de la sala, para la cual se han modificado las barandillas de dichas galerías y ubicar, desde allí, los focos más idóneos. (Foto 11).

\section{c) Sistema de Intercomunicación}

Este sistema comprende una red para pasar órdenes de tipo técnico a través de auriculares independientes del sistema de megafonía.

Desde el puesto de regidor, que se define como punto de control, donde va situada la central de órdenes, parte un trazado a varios puntos de recepción en camerinos, pasarelas del escenario donde realizan sus trabajos los tramoyistas y electricistas en un momento de la función, foso de orquesta al lado del director, galerías de luces en techo de sala, zona de cuadro de regulación en desván, cabina de control y peine. Así pues todos los puntos donde se realizan labores técnicas están intercomunicadas con un circuito interno de comunicación.

\section{d) Sistema de Sonido Profesional}

Se ha instalado un sistema de sonido profesional, con el objeto de poder reproducir o bien un sonido ambiental previamente grabado, o reproducir a través de altavoces representaciones que interesen ser amplificadas.

\section{Instalaciones de Seguridad}

Se entiende por Instalaciones de Seguridad aquellas que sirve para proteger al edifico ante un riesgo de incendio.

Para ello se ha dotado al edificio, en la zona de actuación, de un sistema de detección y extinción de incendios. Se ha protegido la sala con respecto al escenario con un telón cortafuegos en cumplimiento además de la normativa vigente de espectáculos, y se ha protegido la estructura portante de escenario y cubierta.

\section{a) Detección y Extinción de Incendios}

Antes de la realización de las obras de equipamiento técnico, el edificio poseía un sistema de detección y extinción muy en precario, y tan sólo limitado a la zona de vestíbulos y dependencias anexas.

El escenario quedaba por reformar, y por lo tanto de incluirle este tipo de instalación, así como a los camerinos, talleres, cabinas de control de iluminación y sonido, telar, y zona de dimmers.

http://informesdelaconstruccion.revistas.csic.es 
Se han instalado detectores de humos en las zonas que quedaban pendientes. Ante la existencia de un incendio, cualquier detector pasa una señal a la centralita existente en una dependencia cercana al vestíbulo principal.

La extinción se ha realizado en base a dos tipos de actuación: extinción por agua, y extinción por halón.

\section{Instalaciones Especiales}

Se entiende por Instalaciones Especiales a un conjunto de instalaciones que en realidad son complementarias para el funcionamiento artístico de las representaciones teatrales.

En el Teatro de La Vaguada estas instalaciones son las siguientes:

- Sistema de Circuito Cerrado de T.V.

- Sistema de Megafonía.

- Sistema de Intercomunicación.

- Sistema de Sonido Profesional.

\section{a) Sistema de Circuito Cerrado de T.V.}

Esta instalación se basa, esencialmente, en un seguimiento de lo que acontece en escena desde distintos puntos del teatro.

Se han instalado cámaras de seguimiento en las paredes laterales de la sala, en el fondo de la misma para tener una toma frontal sobre el escenario $y$, por último, una en el foso de orquesta para seguimiento de los movimientos de su director.

Para tener un seguimiento de lo que a través de las cámaras se capta, se han dispuesto monitores en el vestíbulo principal y en el vestíbulo de la planta alta, así como en el bar sito en el sótano. Es usual en los teatros tener estos monitores, pues el público que llega tarde a la representación queda retenido hasta que en un entreacto se le permite acceder, sin perjuicio de molestar durante la representación.

Existen también tomas para monitores en los camerinos. La importancia de este sistema en un teatro es vital puesto que, en un momento de representación, los artistas pueden controlar lo que ocurre en escena y saber cuándo pueden acceder a escenario en el momento preciso.

\section{b) Sistema de Megafonía}

Se han dispuesto tres sistemas de megafonía:

1.-Para dar avisos al público y sala. En caso de una evacuación puede ser muy útil.
2.-Para seguimiento de obra y órdenes en camerinos y zonas técnicas.

3. $-Y$, por último, para seguimiento de obra a través del circuito cerrado de TV, anteriormente descrito.

Es un sistema con dos puntos de control: uno en la zona de regidor y el otro en la zona de cabina, existiendo la posibilidad desde cada uno de estos puntos de enviar los mensajes oportunos.

La extinción por agua, corresponde a las zonas de escenario y talleres, y parte superior del telón cortafuegos. Se realiza por medio de sprinklers.

La extinción por halón se realiza en zonas donde ante la existencia de un sofisticado equipamiento la extinción por agua sería totalmente perjudicial. Tales zonas son las cabinas de control de iluminación y sonido y la zona de dimmers y cuadros generales de fuerza, sitos en el desván.

\section{b) El telón cortafuegos}

El telón cortafuegos es el elemento que cubre la totalidad de la embocadura del escenario y lo compartimenta e independiza con respecto a la sala ante la existencia de un fuego. Se ha cumplido asi con la NBECPI 82 y el Reglamento de Espectáculos Públicos.

Ante la existencia de un incendio, la maniobra de bajada del telón se puede hacer bien desde el interior del escenario mediante una botonera que acciona un motor hidráulico, o bien mediante un mecanismo fuera del escenario, pero, según indica el Reglamento de Espectáculos, cerca de él. La resitencia al fuego del telón es de setenta minutos, tiempo que en realidad es mayor pues la preceptiva columna de agua que hay que instalar, paralelamente a él, le protege para más tiempo.

\section{c) Protección de la estructura}

La estructura metálica portante, tanto de escenario como de desvanes, se ha protegido con piroplaster, un material que con un espesor de $4 \mathrm{~mm}$ consigue dar una resistencia al fuego de ciento ochenta minutos. (Foto 12).

\section{Equipamiento}

Dentro del equipamiento que ha completado la instalación escenográfica del teatro, mencionaremos que han quedado completadas con:

- Mesa de regulación de efectos lumínicos.

- Etapas de potencia o dimmers. 


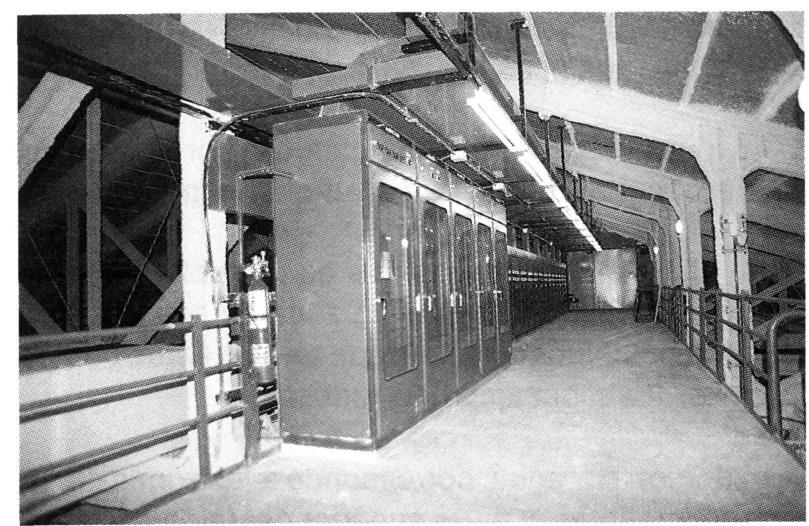

Foto 12.-Instalación de extinción por halón cuadros generales y protección de la estructura en desván.

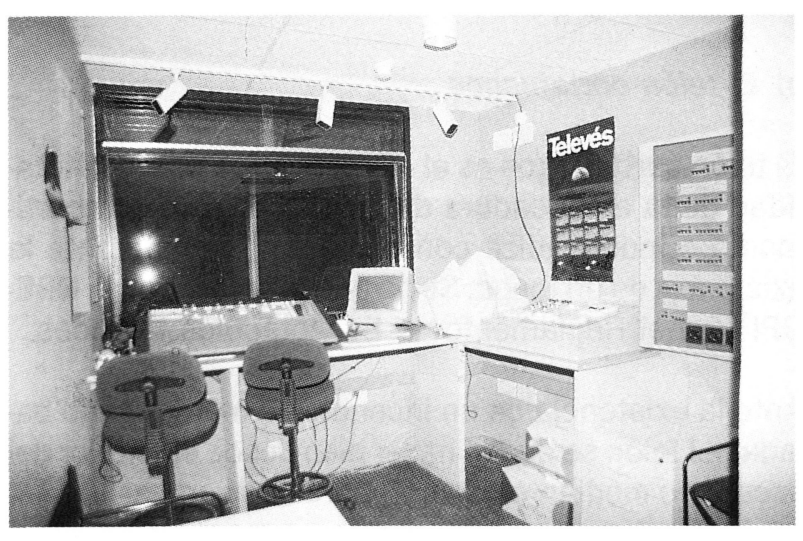

Foto 13.-Equipamiento de regulación efectos lumínicos.
- Focos.

- Equipo de grabación y reproducción de efectos especiales.

\section{a) Mesa de regulación de efectos lumínicos}

Es un pupitre de control de la marca Rank-Strand, dotado con un microprocesador capaz de controlar y regular los circuitos de iluminación de los efectos lumínicos. Consta además de una pantalla de ordenador donde los efectos de iluminación quedan reflejados y controlados, pudiendo quedar grabados en diskettes. (Foto 13).

\section{b) Etapas de potencia o dimmers}

Se denominan etapas de potencia a los circuitos de regulación existentes en la instalación de focos para efectos lumínicos.

Se han instalado hasta un total de 360 etapas en los armarios dimmers situados en el desván, como lugar más propicio entre la zona de control, la cabina, y el escenario donde se realiza la iluminación. (Foto 14).

\section{c) Focos}

Se ha dotado al teatro de un importante número de focos de distintos tipos, según el tipo de iluminación y de efectos requeridos.

\section{d) Equipo de grabación y reproducción de efectos especiales}

Es la instalación de sonido profesional, se ha instalado una mesa de mezclas con las correspondientes cajas acústicas repartidas por la sala, y con tomas por el escenario.

\section{Otras mejoras realizadas}

Paralelamente a la realización de las obras de equipamiento técnico, se han hecho otras que siendo en todo caso funcionales, han sido de complemento para el embellecimiento general del teatro.

Estas, de un modo global, han sido las siguientes:

Suministro de enmoquetado y cortinajes en sala y accesos a la misma.

Creación de un guardarropa.

Pintura de la sala, iluminación del techo y oscurecimiento para representaciones.

http://informesdelaconstruccion.revistas.csic.es 
Los dos primeros puntos no ofrecen en sí mayor comentario que el conseguir un decoro en el aspecto formal del teatro en sus vestíbulos y sala. Se ha realizado un guardarropa nuevo en el vestíbulo principal, pues el que existía era realmente pequeño. (Foto 15).

Requiere mayor detenimiento, el tratamiento dado a la sala.

La misma estaba con los paramentos pobremente tratados y con una pintura que desmerecía frente a la labor que estaba resultando de la realización de las obras en el escenario. Había pues que tratar la sala.

De entrada se producían dos problemas a resolver: uno la iluminación natural que tenía el edificio, y que no se ha perdido; y el otro la pobreza de resultado estético que daba el techo.

La iluminación natural es muy potente en el interior de la sala. Esto hace que, si durante una representación, la iluminación natural del exterior penetra, los efectos lumínicos de la escenografía no se ven realzados, pudiéndose dar el caso de interferencias de haces de luz provenientes de los focos con la luz exterior.

Como por otra parte no se quería eliminar la idea de los arquitectos que construyeron el edificio, de iluminar con luz natural mediante una galería de ventanas en el último anfiteatro, se pensó en la instalación de unas cortinas motorizadas realizadas en "foscurit", para que cuando hubiese una representación de ópera, zarzuela o ballet estén bajadas, no permitiendo la introducción de luz natural y no distorsionando los efectos de iluminación escénica.

El techo era otro elemento a tratar. Cuando se comenzó la obra era una gran masa de color blanco cuyo aspecto más destacable es la formación de los casetones que juegan un papel como elemento acústico, aligerando visualmente por otra parte la gran masa de escayola que constituye el techo.

Con la pretensión de oscurecer la sala, y darle unas entonaciones acordes, se pensó, recordando el cine Skandia del arquitecto escandinavo Gunnar Asplund, pintar el techo en color azul oscuro, es decir, la idea del cielo como bóveda. Con objeto de hacer "desaparecer" visualmente el techo, y para producir la ilusión de un espacio a cielo abierto, en Asplund fue la incorporación de unas redondas y blancas lámparas que, según algunos autores, les sugiere la idea de una mágica noche de "muchas lunas"; aquí, en La Vaguada, y mediante la introducción de una tecnología más moderna, se ha incorporado, bordeando las caras de los casetones, puntas de fibra óptica, que es una red de cables iluminados en su final con una pequeñísima punta, al que se ha completado con una esfera para provocar una radiación proporcionada con la extensión

(c) Consejo Superior de Investigaciones Científicas

Licencia Creative Commons 3.0 España (by-nc)

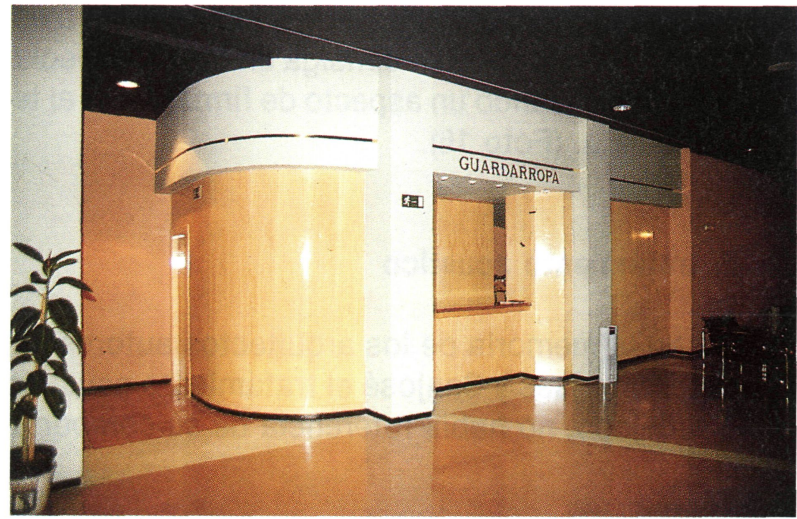

Foto 15.-Guardarropa (Diseño de J. L. de Rojas Herrero).

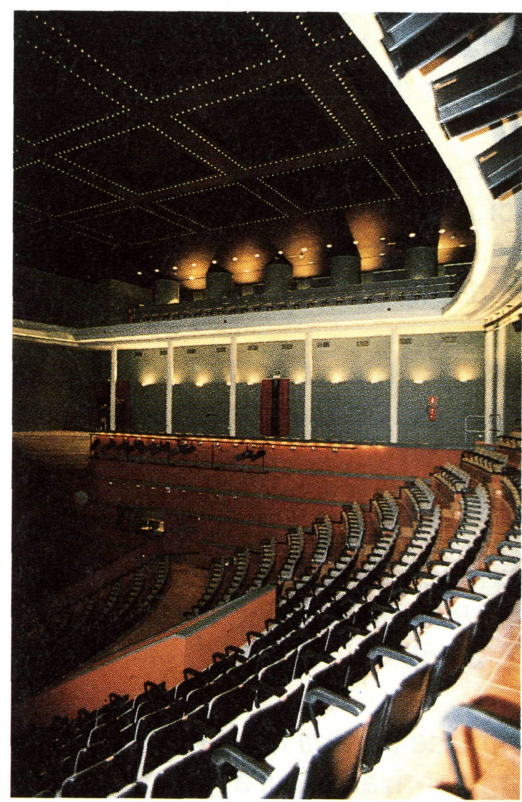

Foto 16.- - Techo de sala (vista parcial).

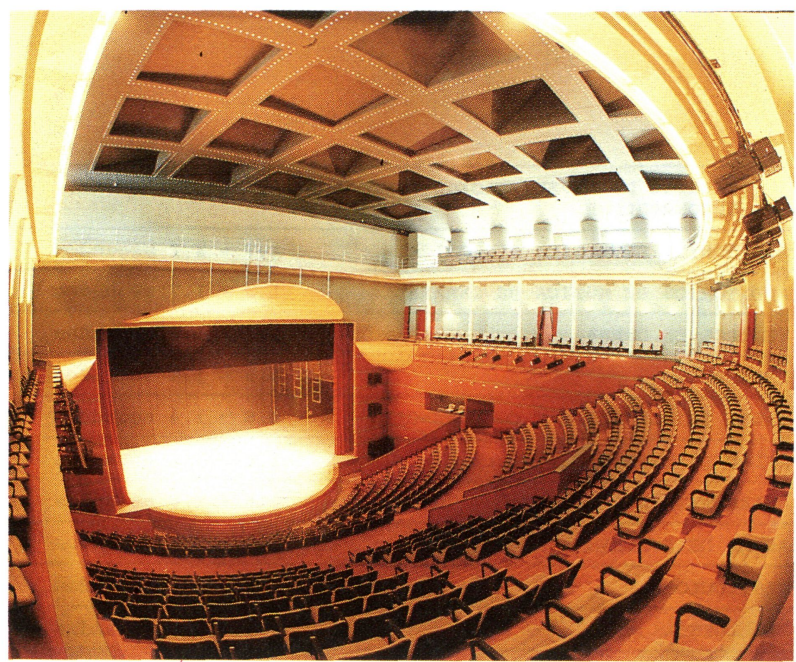

Foto 17.- Vista general de la sala y situación de reflectores sobre embocadura. (Elección tonos de pintura en sala: Guillermo Costa). http://informesdelaconstruccion.revistas.csic.es 
del techo. La graduación de colores incorporada a esta fibra óptica hace que se consiga un efecto especial muy agradable, dando un aspecto de firmamento al techo de la sala. (Foto 16).

\section{El tratamiento acústico}

Si bien en la memoria de los arquitectos autores del edificio Parcerisas y Sanjosé el tratamiento acústico venía reflejado, no había referencia de su comportamiento.

Para ello se encargó a una casa especializada en estos tratamientos un estudio para poder, si fuera necesario, establecer medidas correctoras.

Se partió de la idea de que aquí se podían dar conciertos de bandas municipales y sinfónicas, así como representaciones de zarzuela y ópera.

Habia pues que hacer un estudio sobre el tiempo de reverberación de la sala, viendo si las superficies de los paramentos eran las más adecuadas y la posible incidencia del ruido exterior.

El tiempo de reverberación de un recinto permite medir la permanencia de la energía sonora en el mismo. Para este tipo de edificios su valor es de 1,1 a 1,7 segundos.

El ruido exterior, es decir, la incidencia del ruido de la calle o de los locales colindnates no debe ser superior a 20 ó $25 \mathrm{~dB}$.

De los puntos de partida que la teoría acústica nos expone y pormenorizándolas a nuestro caso se observó que los parámetros aplicables se fijaban en que el tiempo de reverberación debía de situarse entre 1,2 y 1,7 segundos.
La relación volúmen/capacidad de la sala se acerca a $8,8 \mathrm{~m}^{3}$ por persona y que el ruido de fondo del exterior no debía superar los $28-30 \mathrm{~dB}$.

Por la forma de la sala y las dimensiones, existen reflexiones laterales cortas con retrasos inferiores a 40 milisegundos, si bien la forma y capacidad de la sala y las dimensiones de su escenario y foso de orquesta no ofrecen problemas a la difusión del sonido.

Desde el punto de vista acústico la forma de la sala no es problemática, aunque la relación longitud/anchura es prácticamente uno, y ópticamente mayor que uno, por lo que no se estimó que pudiera suponer un problema, máxime cuando las paredes laterales permitian suponer una buena ayuda al sonido con abundantes reflexiones laterales.

La forma del techo era adecuada, pues ofrecía, y de hecho ofrece, unas aceptables difusiones sonoras debido a sus casetones.

No obstante se comprobó que la acústica para conseguir unos tiempos de reverberación debía de ser retocada con la introducción de una acústica variable. $\mathrm{Si}$ bien éste es el sistema más idóneo, ya que permite su regulación según los distintos criterios de directores de orquesta, escénicos, etc, o según los distintos usos, es a veces complejo a la hora de un mantenimiento adecuado.

No obstante se comprobó también que, dadas las características del foso de orquesta e incluso su situación para ser ocupado en modo sinfónico, permitía observar la falta de asistencia mediante reflexiones cortas procedentes del techo o de los laterales hacia la propia orquesta.

Esa ausencia de reflexiones cortas podía suscitar algunas quejas por parte de los músicos, tendentes a

\begin{tabular}{|c|c|}
\hline $\begin{array}{l}\text { TIEMPOS DE REVERBERACION OPTII } \\
\text { RECOMENDADOB }\end{array}$ & FRECUENCIAS \\
\hline AUDITORIOS DE MUSICA SINFONICA & $1.7-2.2$ segundos \\
\hline AUDITORIOS DE MUSICA DE CAMARA & $1.4-1.7$ segundos \\
\hline TEATROS DE OPERA & $1.1-1.4$ segundos \\
\hline TEATROS & $0.8-1.4$ segundos \\
\hline SALAS DE CONGRESOS Y CONFERENCIAS & $0.8-1.4$ segundos \\
\hline SALAS DE ENSAYO & $1.0-1.5$ segundos \\
\hline AULAS ENSENAANZA MUSICAL & $0.6-1.0$ segundos \\
\hline AULAS DE ENSEÑANZA & $0.5-0.9$ segundos \\
\hline VESTIBULOS & $0.5-1.0$ segundos \\
\hline BIBLIOTECAS & $0.5-0.8$ segundos \\
\hline OFICINAS & 0.6 segundos \\
\hline
\end{tabular}

Cuadro del informe acústico de la casa consultora.

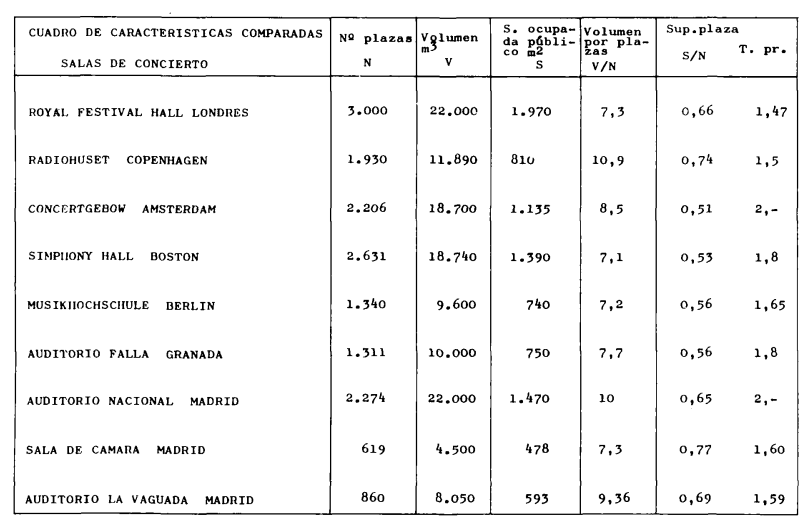

Cuadro de características acústicas comparadas con otros auditorios representativos (de la Memoria de Parcerisas y San José). 


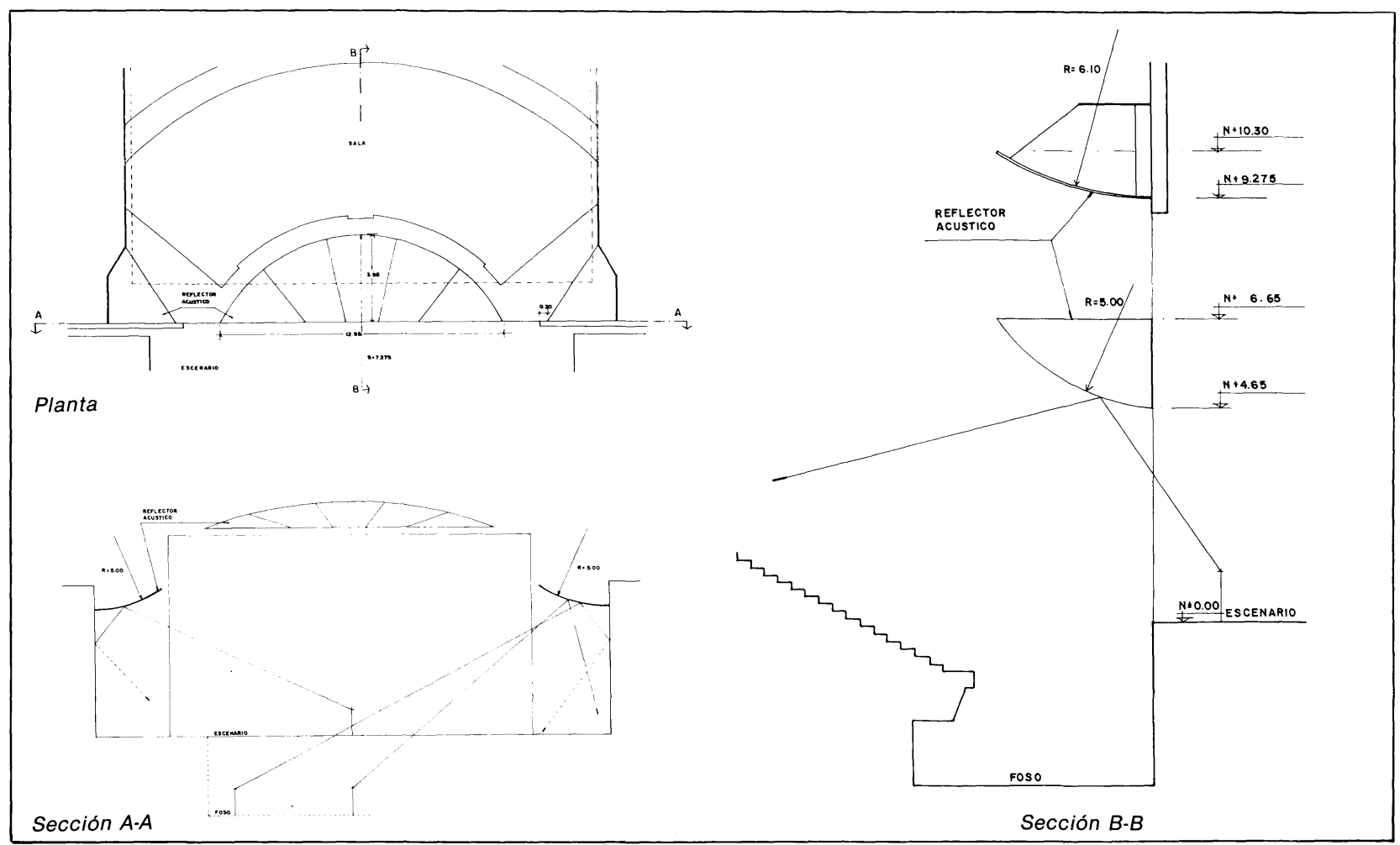

Reflectores acústicos sobre la embocadura.

que entre ellos no se pudieran oír entre sí, es decir, que se notaba la falta de superficies que arropen por su cercania a los músicos.

Por eso el informe acústico que redactó la casa especializada recomendaba la instalación de unos reflectores acústicos que jugaran ese papel en la parte superior de la embocadura, y otros dos laterales en los costados de la sala a la altura del foso de orquesta, permitiendo una mejor audición en las primeras filas del patio de butacas. Estos reflectores, en formas curvas, se han construido en madera de $19 \mathrm{~mm}$ de espesor. (Foto 17).
Esto es, a grandes rasgos, lo que ha supuesto desde su inicio el nacimiento de un nuevo teatro para Madrid, donde se han introducido las nuevas tendencias en arquitectura escenográfica con este proyecto de equipamiento escénico.

Por último quisiera agradecer a los señores $D$. Luis Cuevas Puerta, de la empresa constructora y a D. José Manuel Blasco Maldonado, de la empresa de electricidad, la oportunidad que me proporcionaron para colaborar con ellos en la redacción del proyecto del concurso de equipamiento técnico previo al de realización de estas obras.

FICHA TÉCNICA

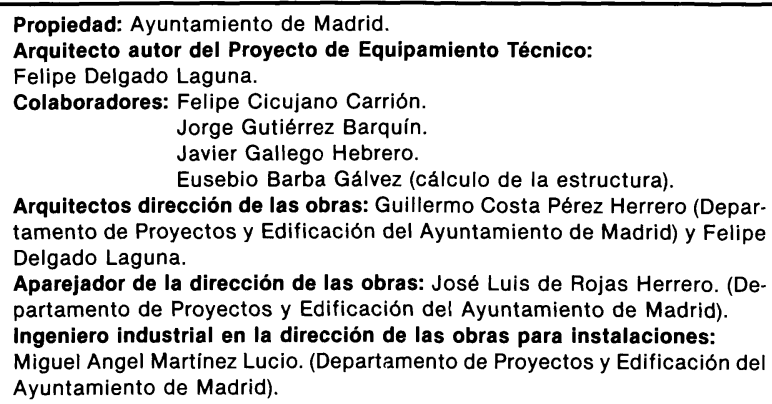

Empresas Constructoras:

CUBIERTAS Y M.Z.O.V. (Estructuras y Acabados).

Jefe de Departamento: Antonio Moreno Ontañón. Jefe de Obra: Gabriel Gómez Robles.

CRESPO Y BLASCO (Instalaciones de Electrificación, lluminación y Sonido).

Jefe de Departamento: Enrique Serrano Vigil.

Jefe de Obra: Enrique Fernández Bas.

KREMESA (Maquinaria escénica).

Jefe de Departamento: Miguel Barba Gálvez.

Jefe de Obra: Juan Martín Garcia.

Empresas Consultoras:

GARCIA BBM (Consultores acústicos).

INTEMAC (Consultores control de la estructura). 